\title{
Article
}

\section{Maternalism: a healthy alliance for recovery and transition in eating disorder services}

Wright, Karen Margaret

Available at http://clok.uclan.ac.uk/13746/

Wright, Karen Margaret ORCID: 0000-0003-0693-7294 (2015) Maternalism: a healthy alliance for recovery and transition in eating disorder services. Journal of Psychiatric and Mental Health Nursing, 22 (6). pp. 431-439. ISSN 1351-0126

It is advisable to refer to the publisher's version if you intend to cite from the work. http://dx.doi.org/10.1111/jpm.12198

For more information about UCLan's research in this area go to http://www.uclan.ac.uk/researchgroups/ and search for <name of research Group>.

For information about Research generally at UCLan please go to http://www.uclan.ac.uk/research/

All outputs in CLoK are protected by Intellectual Property Rights law, including Copyright law. Copyright, IPR and Moral Rights for the works on this site are retained by the individual authors and/or other copyright owners. Terms and conditions for use of this material are defined in the policies page.

\section{CLoK}

Central Lancashire online Knowledge www.clok.uclan.ac.uk

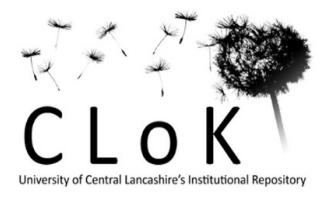


Maternalism: a healthy alliance for recovery and transition in eating disorder services

Karen M. Wright

Principal Lecturer

PhD, MA, PGCert Personality Disorder, PGCert Research, PGCert TLHE, BScHons, RGN, RMN, FHEA

Principal Lecturer

School of Health

University of Central Lancashire

Preston

Lancashire

England

PR $12 \mathrm{HE}$

Phone: 01772893637

Email: kmwright1@uclan.ac.uk

\section{Accessible summary}

- The therapeutic relationship is pivotal to mental health nursing but very little is known about how it is experienced in adult eating disorder services.

- This paper reports on research project which sought to discover how the therapeutic relationship is experienced between care workers and women with anorexia nervosa (AN) in an adult eating disorder service.

- Both care workers and women spoke of a relationship that had similarities to the mother-daughter relationship, that it felt therapeutic and that it was in keeping with a professional and compassionate nursing approach.

- These findings provide new insight. 'Maternalism' is seen as a positive, nurturing and transient relationship that ensures the safety of the person and promotes recovery and transition to eventual independence. 
This paper reports on a U.K. interpretative phenomenological research study which aimed to explore the lived experience of the relationship between women with anorexia and their care workers in the context of a specialist eating disorder unit. Here, the concept of maternalism as a phenomenon occurring within the therapeutic relationship in specialist eating disorder units is discussed. Consideration is given to the parallel roles of the health care worker whose duty it is to protect, preserve life and to promote health and that of a mother/guardian. Although seemingly simplistic, the comforting, soothing and nurturing techniques that are used by the workers to diffuse distress and help the person feel cared for, have many similarities to 'mothering'. Hence a maternalistic approach which provides a sense of security and nurturing can be a compassionate way to facilitate hope and a route out of their anorexia into recovery, in the same way that good parenting can facilitate maturation and independence.

Key words: eating disorder, interpersonal skills, maternalism, mothering, phenomenology, therapeutic relationship.

\section{Introduction}

This paper reflects upon the concept of 'maternalism' as it emerged from an interpretative phenomenological study which explored the therapeutic relationship between women with anorexia and their workers [Full reference to be inserted here later, to protect the blinded review process]. Consideration is given to the parallel roles of the health care worker whose duty it is to protect, preserve life and to promote health, and that of a mother/ guardian, as these emerged from research conducted in two UK eating disorder services.

Of the $1.6 \mathrm{~m}$ people affected by eating disorders(ED) in the UK, 91\% are women (HSCIC, 2013). In 1999, Dolan and Gitzinger attempted to provide some insight into why women suffer more than men from eating disorders and to explore whether women therapists could offer something more than their male colleagues. In their text, 'Why Women?', Dolan and Gitzinger argued that 'normal' women binge eat once a month and that the majority have been on slimming diets; they ask why eating disorders are not actually considered to be 'a disorder of our culture' (Dolan and Gitzinger, 1999: 6). MacSween (1996), on the other hand, presents 
an individual, rather than a societal view, arguing that women suffering from AN believe that thinness will provide a solution to their unhappiness, so they strive to achieve food-control and to seek 'selfhood' (MacSween, 1996: 38).

\section{Relationships in a specialist eating disorder service}

Despite the growing number of eating disorder services in the UK, Serpell et al ,(1999) describe a reluctance to accept treatment. This is undoubtedly because anorexia nervosa (AN) is considered to be highly valued by the sufferers who may also refuse to admit the seriousness of their condition (Paulson-Karlsson et al, 2006). They may believe they are coerced, persuaded or threatened by family, friends and health workers to accept treatment which may create antagonistic relationships with those who try to help them (Goldner, 1989; Giordana, 2005). Abd Elbaky et al (2014) argue that anorexia provides an identity and a sense of selfworth, despite its serious health risks, so it is hard to relinquish. Others accept that they are unwell and seem motivated to recover, but understandably, find the re-feeding treatment very difficult to accept (Paulson-Karlsson \& Lauri Nevonen, 2012).

Palmer (2000) refers to the challenge of creating a therapeutic relationship with women who can be seen as obstructive, subversive and manipulative. He suggests that young women with AN are more likely to be feeling lonely, misunderstood and rather fragile; they seek 'understanding' from therapy, but their attitude affects the worker who then feels unwanted and unvalued. The individual's need for privacy, their fear of intrusion and mistrust of others also suggests that patience, warmth and honesty are paramount to the care process (Shipton, 2004). People suffering from eating disorders seek high levels of human warmth from their care workers, but equally, may not trust the care workers (Kaplan and Garfinkel ,1999); they may crave attention, may make heavy demands on their time and energy, and consequently care workers may experience hostility, anger, hopelessness and stress. 
Women with AN have complex needs and their resistance to treatment presents a challenge to workers. Much of ED inpatient care is delivered by unqualified health care support workers who may have limited professional education. These workers use themselves as the therapeutic tool using intuition and communication skills, often utilising nothing more than 'general conversation' as a tool for engagement (Hayes, 2012; Wright and Wright, 2011). These care workers develop the skills required to sustain a therapeutic relationship as an individual process based upon their own personality, intuition and moral development rather than via academic study (Green, 2006). Additionally, the vast majority of people receiving care and treatment within adult ED services are women, as are the workers.

Oakley (2000) discusses her observation that qualified members of staff also tend to work in this way, irrespective of their professional training, hence, established practice is largely based upon intuitive responses or established custom and practice in that 'professionals do what they think is best, without necessarily having any evidence to support it' (Oakley, 2000: 17). Some of the workers may have had training in the available treatment approaches but find themselves managing the interpersonal relationship as a priority, because engagement with treatment is difficult without establishing trust and acceptance first. Oakley expresses concern that practitioners decide what to do in a very unscientific way based on guesswork, rather than because it has been shown to be safe or effective and that approaches to creating a good, therapeutic relationship may be overlaid with social and parental experiences (Oakley, 2000). Hence, 'Maternalism' might be considered to be a fairly predictable position for women workers, but one that many nurses seek to disguise in an effort to maintain professional boundaries.

'Paternalism' is largely considered to be a disempowering position, where the 'parent' is seen as being the powerful one. It is not gender-specific, and is an institutional construction that overrules the preferences, decisions, or actions of an individual in support of their overall treatment and evokes an oppressive fostering of dependence (Breier-Mackie, 2006; Christensen \& Hewitt-Taylor, 2006). Nurses, as carers, have previously been described by Salvage (1990) as adopting such a disempowering position, arguing that the caring function of nurses may itself be a disempowering phenomenon for patients and refers to this as 'maternalistic behaviour' towards their patients, rather than empowering behaviour. This paper considers the concept of the apparent maternalistic therapeutic relationship occurring within ED services and thus 
poses the question: does maternalism disempower people with AN? or, is it a therapeutic approach which bridges the gap between the person with $\mathrm{AN}$ and the professional carer?

\section{Study aim}

This study aimed to explore the lived experience of the relationship between women with anorexia and their care workers in the context of a specialist eating disorder unit. A phenomenological approach has been adopted, hence, this study aims to shed light, or 'illuminate' (Todres and Galvin, 2008; Smythe et al, 2008) the experience of the relationship between women who suffer with this debilitating condition and care workers striving to help them recover.

\section{Recruitment}

A purposive sampling strategy was adopted in order to ensure that only health care workers and those who were receiving treatment within the adult eating disorder service were able to take part in the research. At the time of the study there was only one man receiving care and treatment in either service, (he was not well enough to take part). The vast majority of the care workers were female. Previous studies into the relationship between patients and care workers have not included the patients as participants in the research (King and Turner, 2000; Ramjan, 2004; Snell et al, 2010). After taking advice from the care teams from both services in the study, I requested information about when it would be appropriate to meet with participants individually. I left two folders containing all the information about the study, the information sheets, my contact details and consent forms, (one in the communal lounge area for the patients and one in the nursing office, for the care-workers). The services were very small and all staff who were available at the times when the researcher was present, consented. All the patients who were well enough to take part did so. Those who did not take part were either not well enough or were not present when the interviews were being conducted. Interviews took place at least 24 hours after consent was given and were conducted by a researcher who was external to the service.

Twelve women with anorexia and thirteen care workers from two eating disorder services were interviewed. The only male participants were two of the health care workers, (both doctors). Demographic details of the participants are detailed in tables $1 \& 2$. 


\section{Ethical approval}

Approval for this study was granted by the NHS National Research Ethics Service as well as the University's Ethics Committee. Pseudonyms have been used to protect confidentiality.

\section{Method}

Van Manen's approach to phenomenological research has been adopted which he describes as:

'A human science research approach, showing a semiotic employment of the methods of phenomenology and hermeneutics'. (van Manen, 1990: 1).

His approach reflects characteristics of both descriptive and interpretive phenomenology (van Manen, 1990) and seeks to bring forth the lived experience of the individual within their own context. Van Manen, influenced by Merleau-Ponty, states that all 'phenomenological human research efforts are really explorations into the structure of the lifeworld' (1990:101).. Van Manen promotes the use of MerleauPonty's existential themes as guides for reflection in the research process (Merleau-Ponty, 1945/1962); these are: 'lived body' (corporeality), 'lived time' (temporality), 'lived space' (spatiality) and, finally, 'lived human relation', (relationality or communality). Merleau-Ponty uses the term 'relationality' in order to conceptualise the 'between space' (Merleau-Ponty, 1945/1962). He asserts that perception cannot occur without perceiving and being perceived by others. Van Manen refers to this as 'the lived relation we maintain with others in the interpersonal space that we share with them' (van Manen, 1990: 104).

A central objective of phenomenology is to query common-sense and everyday experiences in order to understand the phenomena as it is presented to us (Yardley, 2000). Furthermore, phenomenology has been well accepted in caring science research since it is considered to be the attentive practice of 'thoughtfulness', a 'minding', a 'heeding', a 'caring attunement' (Heidegger, 1962), all of which would arguably be compatible with nursing.

\section{The interviews}


A semi-structured interview schedule was utilised and all interviews were conducted by to be inserted later]. Interviews were conducted at the service sites and lasted between 20 and 70 minutes each. Thematic statements were isolated either during the interview, or in follow-up interviews as 'objects for our reflection' (van Manen , 1990) The participants were asked 'is this what the experience is really like?', thus the interview became an interpretive conversation, which enabled the participant to develop the meaning of an experience through conversation (van Manen , 1990).

Van Manen refers to the 'hermeneutic interview' (van Manen, 1990: 98) where he refers to the interviewer keeping the question open and the interviewee orientated to the phenomenon. Polt (1999) uses Heidegger's 'hermeneutic circle' to describe the phenomenological interview as a constant return to the previous descriptions and his re-conception of these in an attempt to make them more accurate and nuanced. Polt suggests that this is more of a 'spiral' than a 'cycle' as each turn of the cycle 'reaches a deeper level' (Polt, 1999: 31) which enables exposure of the phenomenon and accurate interpretations in the analysis. Hence, participants were interviewed as many times as necessary to enable them to describe their lived experience of the therapeutic relationship as fully as they were able.

The full data set was uploaded into MAXQDA software, enabling sections of the interviews to be coded and then compared against each other for similarity and difference, resulting in some areas being re-coded or classified as sub-codes.

\section{Findings}

Only the study findings related to the participants' experience of 'maternalism' will be considered here.

\section{Maternalism and 'mothering'}

Although there were attachments formed between the care workers and the women, they did not seem to confuse the boundaries of the professional maternal role. The relationships that were compared to 
'mothering' or 'maternalism' appear to be productive and to assist in the journey to recovery. They were candid in their disclosure of their emotional distress and their need for this to be responded to by physical comfort. The comfort offered may be provided by one woman (all the nurses in the study were women) to another (a patient) and this was seen as helpful. In some cases, comfort was also offered by a patient to another patient.

Some care workers spoke about falling, intuitively, into the mothering role, some of the women searched for 'mother figures' and felt protected by them, whereas others ran from 'mother figures'. Some of the participants (from both groups) spoke of behaviour more usually attributed to children or adolescents using terminology such as 'tears and tantrums' and 'messing about'. Others, like 'Debbie' appreciated the sense of normality and familiarity created by the presence of somebody who was 'like a mum'. Her description created the image of a reciprocated relationship where Debbie feels that she matters and normality is established, even in hospital:

'Well she's a similar age to my mum, so it's kind of like a mum kind of figure. She's really funny, just open, just treats me like a normal person. She chats to me about anything; she comes to my room and reassures me that everything's going to be alright. She tries not to make a big emphasis on the food and all around as normal everyday life, she's really caring and sensitive to like any of my needs and anything that I need. She's just always there. '

Debbie, Patient

'Motherliness' meant a protecting, comforting person for Libby. She felt that she needed the maternal-style approach because she was feeling vulnerable and child-like. Hence, when the nurses behaved in that way an association was made that reinforced that the relationship was caring and protective:

'And they were like motherly, like I don't know, just the way they acted with you, it's like they were wrapping you in cotton wool almost, which was good because I was very sort of in a fragile state at the time. I don't know how to describe it; it just felt like you were a little child being cared for.'

Libby, Patient

Donna felt that she gravitated toward a particular nurse, because she was a 'mother-figure':

'... maybe she's a bit of a 'mother figure'... I haven't had a mother in my life either and maybe that's what I want - that's why I gravitate [towards particular workers]'. 
Donna, Patient

Equally, some of the women disclosed that they either felt child-like, or that an interaction resonated with a child-adult transaction. Anna recognised that Lizzie cared about her when she sat down next to her:

'Yes because when I'm upset I go and sit on the floor in a corner somewhere. I don't know why, it just feels safer. And she'll always come and sit on the floor, whereas somebody else would just stand at the door and say, come on, are you coming and stand in front of you so you have to look at them, then that's a bit more intimidating I think. Whereas she'll come down, like you do with a child I guess.'

Anna, Patient

The physical closeness and the worker's presence was seen as important to Debbie, (patient) who enjoyed the sense of somebody simply 'being there', or putting their arm around her and Donna (patient) appreciated the 'gently nurturing relationship' but Lizzie (nurse-manger) was aware that it was important to reinforce that the relationship was a professional one, despite the cathartic or emotional nature of the interaction:

'Yes and then you have to start to let them go, because at the end you have to start to withdraw, otherwise your boundaries, because you have to be constantly aware don't you, that this relationship, even though it can be very, very intense at times, it can only ever be what it is, it is a nurse : patient relationship.'

Lizzie, Nurse manager

Sometimes, the comforting presence of a care worker and a much needed hug helped when the women were struggling. Sometimes, the small touch of a hand created a connection that was gentle and evoked a sense of mutual appreciation and understanding between care worker and woman that minimised the need for words. Kelly, a health care assistant, understood this:

'And then she just like, put her hand on mine and just said, I'm struggling' Kelly, Health care assistant.

For Lucy, ( who was attending only for review at the day-care service), her relationship with Eva was the key to her recovery, because through this professional companionship she realised that she was 'perfect just the way I was'. This realisation occurred because somebody (Eva) believed in her enough to help her to believe in herself. 


\section{Discussion}

The participants interviewed for this study clearly appreciated aspects of what felt like a traditional mothering role in terms of its focus on comfort, nurture and care. Aspects of the nursing role have similarities to parenting, such as providing a comfortable, homely environment, meals, offering nonjudgement support, helping with washing and dressing. It was not usual for the women to seek physical comfort (hugs) and to cry on the shoulders of the nurses. The nurses responded with comfort, wiping away tears and stroking their hair away from their faces, for example. The care workers in both services made many references to the need to 'be with' or to 'hold' the women in their care. Indeed, both Benner (1984) and Shipton (2004) agree that the therapeutic relationship is more about being than doing. Benner refers to 'presencing' as to mean 'being with' the person rather than 'doing to' (Benner, 1984: 57). In this way, workers demonstrably show that they care, as Yalom states: it is the 'therapeutic act, not the therapeutic word' that is pivotal to the relationship (Yalom, 2002:38); thus the care worker participates in the person's experience (Benner and Wrubel, 1989) and ultimately uses themselves as a therapeutic agent (Freshwater,2002). Bordin, who emphasises the essential presence of a bond for an alliance to be established, argues that it needs to be a reciprocal relationship (Bordin, 1979). Arguably, a therapeutic relationship is about the 'being with', or, 'being there' (Solomon, 1972).

Bordin asserts that there are three central tenets to the therapeutic alliance; the 'goal', the 'task' and the 'bond' (Bordin, 1979). He suggests that all three must be mutually agreed and collaboratively addressed. The clinical treatments, including re-feeding and weighing can be seen as the tasks of the treatment. Weight gain is usually the goal of the treatment. The apparent disagreement that occurs around both the task and the goal in the work with women with AN might appear to render the model untenable as two of the three conditions are frequently in conflict. Neither the goals nor the tasks of the therapy are readily agreed upon. However, the significance of Bordin's tripartite model, in this context, is its apparent split between that which is clinical, (the goal and the task) and that which is relational, (the bond). The women in this study, however, found that the time they had with care workers that focussed on them and thus established a bond with their workers, rather than achieving a task, was particularly meaningful as this assists in the creation of an authentic relationship. This is particularly true for those in the latter stages of their recovery 
from AN who are 'supervised' less on the ward. Unfortunately, staff attention is frequently drawn to those patients who are struggling to accept the treatment, but those who have made small steps towards recovery still require staff to maintain high level of engagement and continuing positive and encouraging support.

Benner talks of 'presencing' in terms of the sense of security created by simply being with another (Benner, 1984) this is further reinforced by May (1983) who when talking about the therapist's role, says:

'The therapists' role is to be there'. (May, 1983: 163.)

May (1983) also makes the link between with self-awareness and suggests that when a person is accepted, then this frees the person to be their own being. Acceptance is a complex process in a specialist eating disorder service since acceptance of the person might infer acceptance of their altered image of themselves and thus create collusion. The person's recognition that they can be accepted by another person is therefore liberating. Acceptance has to be of the person and their potential, rather than merely their current physicality. May asserts that the self ('being') is not merely the person you are currently, but also the person that you have the potential to be, as can be reflected in the quote from 'Lucy' regarding her relationship with her worker, Eve, who could see her potential (May, 1983).

Yalom presents a premise that 'it is the relationship that heals' (Yalom 1980: 5) and speaks of the genuineness and 'realness' required of the worker, thus reinforcing the authentic, intuitive caring responses which were evident within the eating disorder services studied. We rarely speak of 'loving' our patients and yet this was the request made by some of the women in this study and which resonates with Campbell's 1984 text, 'Moderated love: a theology of professional care'. Campbell suggested that nurses should indeed love their patients within the concept of companionship, personal involvement and giving to the patient, whisoch transcends skill or technique to create a truly loving care. More recently, Stickley and Freshwater (2002: 253) propose that we '...foster a therapeutic alliance that is founded within love' in order to realise its healing potential.

Peplau identified the nurse as a 'mother-surrogate' (Peplau, 1952: 129) due to the dominance of females in the workforce at the time of her study and also the feeding and nurturing role of nurses (Peplau, 1952:51). The vast majority of care workers in this setting are female, as are the individuals that they care for. Clarkson, 
talking from a therapist's perspective, says that we respond in the same supportive way that a mother does in calming the anxious and reassuring the frightened, but without the personal feelings that a mother has for their child (Clarkson, 2003). Certainly, some of the women overtly attributed a 'mothering' role to some of the nurses, perhaps as an idealistic substitute for a mother they missed out on earlier in life. It is also possible that the care workers, when responding to vulnerable individuals drew on intuitive responses similar to a parental style of nurturing and protecting those in their care, resonating with Oakley's work, (Oakley, 2000). Oakley also suggests that the way a person constructs the therapeutic relationship may be affected by their own parenting experiences, thus reinforcing the connection with maternal ways relating to others in our care. Similarly, Bowlby provided some insight into why some adult relationships are determined by early experiences of parental attachment (Bowlby, 1980). The sense of attachment and being cared for resonates with Gilbert's reference to 'safe others' (Gilbert, 1989), that is, people (male or female) who foster a sense of safety and protection.

The term 'maternalism' is used here as an alternative to 'mothering' or 'motherliness' and isn't genderspecific as there were indications that some of the women receiving care identified their workers as parent figures. In this study, like that of Dolan and Gitzinger (1991), the women are seen as child-like and their physical and emotional care is largely provided by women. This differs from the possible regression to ' child-like' ways in both appearance and behaviour, that may be otherwise assumed (Marlow, 2013). Indeed, Jones and Malson suggest that the thin body of the anorexic woman may signify 'the petite fragility, selfdenial and child-like status of traditional femininity' (Jones and Malson, 2011:64). Yet, the findings of this study suggest that the women, although physically fragile and dependent upon the workers for care and for feeding, were aware of a maternal-style relationship that they acknowledged was temporary. The maternal relationship eased their distress with kindness that felt like being wrapped in cotton wool in order to protect their delicate selves whilst they recovered. 
The maternalistic approach seen here as personal and individual, is used to describe a worker who cares about the person as well as for them. Maternalism also better reflects the protective, feeding and nurturing role that is adopted by the care workers (Christensen and Hewitt-Taylor, 2006), rather than Peplau's 'mother-surrogate' therapeutic role (Peplau, 1952:129), where the patient's casting of the nurse into a mothering role always occurs 'outside of his awareness' (Peplau, 1952: 51). Maternalism thus occurs unconsciously, as described by Peplau, but also purposefully within the eating disorder service. Workers may choose to adopt a maternalistic style out of necessity, when negotiating the nutritional elements; it is always individual and related to the concern expressed for the vulnerability of the person and without jeopardising the professional, boundaried relationship. It is not, as previously, considered to be disempowering (Salvage, 1990). Yalom, (speaking about therapists), challenges the notion of professional boundaries, exhorting:

'Let your patients matter to you, let them enter your mind, influence you- and not conceal this from them'.

(Yalom, 2010: 26)

\section{What the study adds to existing research}

It is clear that some kind of relationship that has therapeutic effects exists in eating disorder units which may be related to a 'maternalistic' nurturing and protecting approach which seeks to 'save' individuals from dying of starvation who are responding to the 'rescue' rather than the treatment goal (Wright and Hacking, 2012).

Previous studies have focussed on the difficulty of caring for people with an eating disorder, but have tended to focus on adolescents and have not included adults with an eating disorder as participants in the study. Whilst there is some transferability from existing studies, this cannot be taken for granted without specific studies, such as the present one. Previous studies into the 
therapeutic relationship, considered within eating disorder services, have also focussed on the perspective of the worker, rather than the patient (Wright, 2010). This study found that, despite the adult age of the patients, they found the maternalistic, mothering style of workers to be therapeutic.

\section{Implications for mental health nursing: Maternalism as a tool for transition}

The framing of the relationship within a 'maternalistic' context can be helpful provided that it is viewed as temporary and intended to promote eventual maturation, independence and separation from the mother-figure. The recovery aim for many of these women was to remain 'safe' until such a point that they were ready to relinquish their disorder, be discharged, and reclaim their usual position in society. Indeed, the word 'recovery' conjured up thoughts of weight gain and the possibility of attaining a 'normal weight', hence the term 'transition' has been used here to reflect the move from services during the recovery process as well as the physical changes apparent during this process (Wolfe, 2003).

The workers in this study were clear that they needed to demonstrate that they believed that the women could and would recover; offering hope to the women and preparing them for their transition to less intensive services. Indeed, Byrne and colleagues (2013: 199) cite a service user as saying that 'believing in person and offering hope' is pivotal to recovery. Hope that a better future is possible is clearly pivotal to recovery and a concept which is also reinforced by Repper and Slade (2012) who write that 'It is not possible to rebuild your life unless you believe that a decent life is possible and have people around who believe in your possibilities' Repper and Slade (2012: 33).

Anorexia is a highly complex disorder, mentally and physically. The women in this study suffered immensely and needed the sensitive and nurturing touch of people who showed them unconditional care and compassion. 'Mothering' is indeed unconditional, as in Rogers' expectation , that we might 
provide unconditional positive regard in our interactions (Rogers et al, 1967). Although seemingly simplistic, the comforting, soothing and containing techniques that are used by the workers to diffuse distress and help the person feel cared for have many similarities to mothering/ parenting. Workers in this study were unafraid to offer physical comfort and did so in a way that was professional, compassionate and literally 'held' the women in a way that offered them both physical and emotional security. Sadly, human connections such as this are too frequently regarded as 'breaching professional boundaries' shaped by what O'Shea calls 'therapeutic correctness' (O'Shea, 2000:9), particularly within forensic or adolescent services (Pazaratz, 2001; Pilgrim, 2001) Therapeutic boundaries are consequently set at a very conservative default level thus effectively acting as a protective line of separation (Wright et al, 2007). It is crucial that we consider the uniqueness of this setting, the interpersonal dynamics that are played out in specialist eating disorder services and thus re-interpret how professional boundaries can occur which strengthen the therapeutic relationship without weakening the perceived professionalism of the workers.

Compassionate care involves a human connection that is valued by women with AN, who embrace the authenticity of workers and knowingly accept that they are providing a motherly presence whilst they are made vulnerable by their physical frailty and their distress. It could be said that such a relationship is the relocation of an earlier mother-daughter experience, thus revisiting a past relationship in a current situation. If this was occurring sub-consciously and the workers were responding in a maternal way, then this might reflect the transference/ counter-transference relationship which is described by Freud (1915). The findings of this study, however, suggest that women with anorexia may purposefully seek out a 'mother-figure' and that the workers, in turn, are aware of the value of such a nurturing response in return. Hence a maternalistic approach which is short term and provides a sense of security and nurturing can be a compassionate way to facilitate hope and a route out of their anorexia into recovery, in the same way that good parenting can facilitate maturation and independence. 


\section{References}

Abd Elbaky G, Hay P, le Grange D, Lacey H, Crosby R, Touyz S. (2014) Pre-treatment predictors of attrition in a randomised controlled trial of psychological therapy for severe and enduring anorexia nervosa. BMC Psychiatry 14:69.

Benner, P. (1984) From Novice to Expert: Excellence and Power in the Clinical Nursing Process._Menio Park: Addison-Wiley.

Benner, P. and Wrubel, J. (1989) The Primacy of caring: Stress and coping in health and illness. Reading, MA, US: Addison-Wesley/Addison Wesley Longman

Bordin, H. (1979). The generalizability of the psychoanalytic concept of the working alliance. Psychotherapy: Theory, Research and Practice, 16, 252-260.

Bowlby, J. (1980) Loss: Sadness and depression. Attachment and Loss Volume 3._London: Hogarth Press.

Breier-Mackie, S. (2006) Medical Ethics and Nursing Ethics: Is there really any difference? Gastroenterology Nursing 29 (2): 182-3.

Byrne, L., Happell, B., Welch, T., \& Moxham, L. J. (2013). 'Things you can't learn from books': Teaching recovery from a lived experience perspective. International Journal of Mental Health Nursing, 22(3), 195-204.

Campbell, A. (1984) Moderated Love a Theory of Professional Care._London: Society for Promoting Christian Knowledge.

Christensen, M., and Hewitt-Taylor, J. (2006) Modern nursing. Empowerment in nursing: paternalism or maternalism? British Journal of Nursing, 15 (13), 695-699. 
Clark, M. and Nayar, S. (2012) Recovery from eating disorders: A role for occupational therapy.

Clarkson P. (2003) The Therapeutic Relationship (2 $\left.{ }^{\text {nd }} E d\right)$ London: Whurr.

Dolan, B. and Gitzinger, I. (1999) Why Women? Gender Issues and Eating Disorders. London: European Council on Eating Disorders.

Freud, S. (1915) Observations on Transference Love, Hogarth, London.

Freshwater, D. (2002) Therapeutic nursing in Freshwater D., Therapeutic Use of Self in Nursing._(Ed.), London: Sage.

Gilbert, P. (1989) Human Nature and Suffering._London: Lawrence Erlbaun Associates.

Giordana, S. (2005). Understanding Eating Disorders. Oxford: Clarendon Press

Goldner, E. (1989) Treatment refusal in anorexia nervosa International Journal of Eating Disorders 8 (3) 297-306.

Green J. (2006) Annotation: The therapeutic alliance- a significant but neglected variable in child mental health treatment studies Journal of Child Psychology and Psychiatry. 47(5) 425-435.

Hayes, C. (2012) The therapeutic alliance in healthcare assistant practice. British Journal of Healthcare Assistants. 6 (2)78-83.

Heidegger M. (1962) Being and Time New York: Harper and Row.

HSCIC, (2013) http://www.hscic.gov.uk/article/2239/Eating-disorder-hospital-admissions-rise-by-16per-cent-in-a-year [accessed 20th November 2014]

Jones, R. and Malson, H. (2011) A critical exploration of lesbian perspectives on eating disorders. Psychology and Sexuality, 4 (1). 
Kaplan A.S. and Garfinkel P.E. (1999) Difficulties in treating patients with eating disorders: a review of patients and clinical variables. Canadian Journal of Psychiatry 44 665-670.

King and Turner, 2000;

MacSween M. (1996) Anorexic Bodies: A Feminist And Sociological Perspective On Anorexia Nervosa London: Routledge.

Marlow, A. J. (2013). A Quantum Psychopathological Account of Anorexia Nervosa. Neuroquantology, $11(1), 63-82$

May, R. (1983) The Discovery of Being._New York: W.W. Norton and Company.

Merleau-Ponty, M. (1945/1962) (C. Smith, Trans.). Phenomenology of Perception Abingdon: Routledge and Kegan Paul.

New Zealand Journal of Occupational Therapy 59 (1) 13-17.

Oakley, A. (2000) Experiments in Knowing: Gender and Method in the Social Sciences. Polity Press: Cambridge.

O’Shea L. (2000) Sexuality: old struggles and new challenges. Gestalt Review 4(1), 8-25.

Palmer, R. (2000) Helping People with Eating Disorders. Chichester: John Wiley.

Pazaratz, D. (2001). Defining and describing the child and youth care worker's role in residential treatment. Journal of Child and Youth Care, 14 (3), 67- 77.

Paulson-Karlsson , G \& Nevonen, L (2012) What Do Patients Expect from Treatment for AN? Eating Disorders Review, 23(5), 10 
Paulson-Karlsson, G., Nevonen L and Engstrom I (2006) Anorexia nervosa: treatment satisfaction Journal of Family Therapy 28 293-306.

Peplau, H.E. (1952) Interpersonal Relations in Nursing. New York: GO Putman's Sons.

Perkins, R., \& Slade, M. (2012). Recovery in England: Transforming statutory services?. International Review of Psychiatry, 24(1), 29-39

Polt, R. (1999) Hiedegger, an Introduction. Abingdon: Routledge.

Ramjan L.M., (2004) Nurses and the 'therapeutic relationship': caring for adolescents with anorexia nervosa. Journal of Advanced Nursing_45 (5) 495-503.

Reading, MA, US: Addison-Wesley/Addison Wesley Longman

Rogers, C. (1961) On Becoming a Person._Boston: Houghton Mifflin.

Salvage J (1990) The theory and practice of the 'new nursing'. Nursing Times 86(4): 42-5

Serpell, L., Treasure, J., Teasdale, J., et al. (1999) Anorexia nervosa: Friend or foe? A qualitative analysis of the themes expressed in letters written by anorexia nervosa patients, International Journal of Eating Disorders 2577.

Shipton, G. (2004) Working with People with Eating Disorders Basingstoke: Palgrave M Macmillan.

Smythe, E., Ironside, P., Sims, S., Swenson, M., and Spence, D. (2008) Doing Heideggerian hermeneutic research: a discussion paper. International Journal of Nursing Studies, 45 (9), 1389-1397.

Snell, L., Crowe, M. and Jordon, J. (2010) Maintaining a therapeutic connection. Journal of Clinical Nursing. 19 351-358.

Solomon, R. (1972) From Rationalism to Existentialism. The Existentials and their Nineteenth Century Backgrounds. New York: Harper and Row. 
Stickley, T. and Freshwater, D. (2002) The art of loving and the therapeutic relationship. Nursing Inquiry. 9(4) 250-256.

Todres, L., and Galvin, K. (2008) Embodied interpretation: a novel way of evocatively re-presenting meanings in phenomenological research. Qualitative Research, 8 (5), 568-583.

van Manen, M. (1990) Researching Lived Experience: Human Science for Action Sensitive Pedagogy, State university of New York Press, Albany, New York.

Wolfe, K. B. (2003). Treatment Transitions: Improving Patient Recovery Through Effective Collaboration. (Cover story). Eating Disorders Review, 14 (5), 1.

Wright, K.M. and Hacking S. (2011) An angel on my shoulder- the lived experience of the therapeutic relationship between women with an eating disorder and their workers. Journal of Psychiatric and Mental Health Nursing. 19 (2):107-15.

Wright, K.M.; Wright, C.E. (2011) Self harm, suicidal feelings and compassionate care. British Journal of Healthcare Assistants, 5 (8): 378-82.

Wright K., McKeown M., Haigh K (2007) Reclaiming the Humanity in Personality Disorder International Journal of Mental Health Nursing 16(4) 236-246

Yalom, I. D. (2010) The Gift of Therapy. London: Piatkus.

Yalom, I.D. (1980) Existential Psychotherapy. New York: Basic Books.

Yardley, L. (2000) Dilemmas in qualitative health research. Psychology and Health. 55 215-228. 
